DOI 10.37882/2223-2982.2020.12-2.29

\title{
СУБСТИТУЦИЯ ГРАФЕМ В АНГЛИЙСКОМ И ФРАНЦУЗСКОМ ЯЗЫКАХ КАК ОДИН ИЗ ЭТАПОВ УНИФИКАЦИИ ОРФОГРАФИИ (НА МАТЕРИАЛЕ ЛИТЕРАТУРНЫХ ПРОИЗВЕДЕНИЙ)
}

\section{GRAPHEME SUBSTITUTION IN ENGLISH AND FRENCH AS ONE OF THE STAGES OF ORTHOGRAPHIC UNIFICATION (BASED ON THE LITERARY WORKS)}

Yu. Smakhtina A. Ageeva

R. Yakhina

Summary: In Europe, the 17th and 18th centuries were marked with the active orthographic unification processes due to the spread of typography. The unification was divided into many smaller cases. The process of standardization of each of them was not homogeneous. This article is dedicated to substitution of the graphemes $-y-$ and $-\mathrm{i}$ - in English and French. The unification processes do not take place simultaneously, in England it is the 17th c., in France it is the 18th c. However, it presents to be interesting how the identical phenomena develop in different intralinguistic and extralinguistic realities. The article is provided with the examples of the words marked with grapheme substitution at different stages of unification. In the end of the article you can find a concise table containing some intermediate and final results.

Keywords: orthographic norm, typography, standardization, written language.

\section{Смахтина Юлия Вадимовна}

преподаватель, Казанский Национальный Исследовательский Технический Университет им. А.Н. Туполева - КАИ

juiasmahtina@mail.ru

Агеева Анастасия Владимировна

Д.филол.н., дочент, Казанский (Приволжский)

Федеральный Университет

anastasia_ageeva@mail.ru

Яхина Рузиля Раифовна

К.филол.н., Казанский Национальный Исследовательский Технический Университет им. А.Н. Туполева - КАИ RRYakhina@kai.ru

Аннотация: В 17-18 веках в Европе шли активные процессы стандартизации орфографии в связи с распространением книгопечатания. Стандартизация дробилась на множество явлений, и унификация каждого из них проходила не гомогенно. В статье мы рассматриваем такое явление, как субституцию графемы -у- на -і- в английском и французском языках. Процессы унификации проходят в разное время: в Англии в 17 в., во Франции в 18 в., однако интересно понаблюдать, как идентичные по природе явления развиваются в разных интра- и экстралингвистических реалиях. В статье приводятся примеры слов, в которых происходит субституция графем, на разных этапах унификации, а в конце представляется краткая таблица с промежуточными данными и итогами.

Ключевые слова: орфографическая норма, книгопечатание, стандартизация, письменно-литературный язык.
$\mathrm{H}$ ачало эпохи книгопечатания в Европе обратило внимание на огромные пробелы в систематизации орфографии языков, поскольку как таковых правил и норм, определяющих функционирование орфографии, до определенного периода не существовало. Появление книгопечатания и необходимость формирования универсального письменно-литературного языка в пределах своего государства неизбежно повлекли за собой существенные перемены на всех уровнях системы языка, в том числе в орфографии. В статье мы поговорим об одном из явлений унификации, которое наблюдалось в английском и французском языках и было идентичным для обоих языков. Стоит отметить, однако, что периоды стандартизации для изучаемых нами языков приходятся на разные столетия (17 и 18 соответственно), но исторический контекст в обоих случаях во многом схож.

Обсудим для начала исторический контекст, стоящий за унификацией орфографии в Англии и Франции. О необходимости реформирования английской орфографии стали писать уже в конце среднеанглийского периода (11-15 в.), но наибольшего размаха это движение достигло в ранний новоанглийский период. Остается открытым вопрос о том, что, во-первых, считать началом этого периода и, во-вторых, что послужило наибольшим толчком для идей о реформировании. На данный момент рассматриваются две версии. Согласно первой, начало периода приходится на 1400-1450 гг. (появление работ первых художественных произведений на английском поэта Джефри Чосера и последние крупные фонетические изменения в языке). Согласно второй версии, новоанглийский период начинается в конце 15 в. (первая печать книги на английском языке "The Recuyell of The Historyes of Troye" в 1473 г. и основание Уильямом Кэкстоном первого издательства в Вестминстере в 1476 г.). Мы придерживаемся мнения, что ранний новоанглийский период начался с выходом работ Дж. Чосера, поскольку это послужило толчком для формирования общелитературного языка, тогда как за начало орфографического реформирования в языке напрямую ответственно появ- 
ление машинной печати.

Таким образом, необходимость унификации орфографии кажется вполне естественной. С появлением печати количество выпускаемых книг растет с каждым годом. В то же время письменные источники тех времен грешили немыслимым орфографическим разнообразием, если не беспорядком, что происходило по следующим причинам. Во-первых, из-за разницы региональных вариантов английского и невозможности быстрого и частого сообщения между регионами, то есть поскольку фонетические нормы для разных регионов государства разнились, писатели, ориентируясь в основном на принципы фонетического письма, создавали всё новые и новые формы написания одного и того же слова. Вовторых, в то время не существовало как такового серьезного свода правил, который бы определял графемнозвуковое соответствие в языке. Писателям приходилось самостоятельно справляться с этой проблемой и буквально изобретать способы выражения некоторых звуков на письме.

Что касается исторического контекста унификации орфографии французского языка, в нашей статье мы будем рассматривать французскую литературу и язык 18 века, поскольку активные мероприятия по избавлению орфографии от архаичности и бессистемности начались только в 17 веке. Нормирование языка на всех уровнях было тесно связано с историей развития французской нации. Один из признаков ее единства является принцип единства употребляемого языка. Письменно-литературная традиция уже с 13 века постепенно работала над переходом французского языка от языка народности к языку нации, однако не все это было возможно в связи с большим количеством диалектов, говоров и даже форм другого языка, как в присоединенной к Франции немецкой провинции Эльзас. Низкий уровень мобильности граждан из региона в регион не позволял единой норме французского создаваться и распространяться. Проблемой был и низкий уровень образования вне столицы: в 17 веке в провинциях в среднем 1 человек из 100 имел начальное образование в связи с тем, что школы не поддерживались государством, а работали при церквях за счет пожертвований и строились на отдаленном расстоянии друг от друга, вследствие чего далеко не всем гражданам было легко до них добираться. Кроме того, вместо французского языка в школах до 17 века преподавалась латынь, как и в высших учебных заведениях Франции, а обучение велось на местных диалектах, хотя даже в 17 веке процесс становления французского языка общенациональным и государственным завершен не был. Несмотря на то, что книгопечатание во Франции появилось примерно в одно время с Англией, вопросы унификации орфографии по-прежнему требовали решения. Необходимость в систематизации норм общелитературного языка чувствовалась также в разнице произноситель- ных и письменных норм языка.

Образованные придворные круги Парижа в 17 веке проявили интерес к темам литературы и языка. Ими создавались кружки и салоны, в которых обсуждались вопросы грамматики, лексики, фонетики, орфографии французского, что уже можно было назвать первым шагом к стандартизации и нормированию языка. Кроме того, после того как языком государственных учреждений стал французский, дальнейшее распространение норм было неизбежным. Проблемой являлось лишь то, что считать нормированным языком - язык литературный или язык разговорный - и какого из слоев общества. На этой почве весь 17 век не умолкали споры между представителями консерваторских и прогрессивных движений.

B нашей статье мы обратим внимание на явление субституции графемы -у- на графему -і- в английском и французском языках и стандартизации написания слов с ними, рассмотрим унификацию поэтапно и сравним результаты.

В текстах английских произведений начала 17 столетия многие слова, употребляемые на тот момент с графемой -i-, выглядели иначе и использовали в данной позиции гласную -у-. В основном, это были заимствованные слова французского или латинского происхождения. Причина тому кроется в этимологии этой лексики и в тенденции сохранения первоначального облика заимствований. Как будет описано в нашей работе впоследствии, во французском языке нового периода происходил тот же процесс субституции -у- на -і- в различных позициях вследствие прекращения соответствия фонемного облика звука, передаваемого графемой у, ожидаемой в данной позиции фонеме. Субституция этих графем в английском языке происходила, возможно, также вследствие осознания неверной репрезентации графемой ожидаемой фонемы. Кроме того, при жизни Дж. Чосера графема -у- заменила графему -і- в словах, где ее окружали буквы $\mathrm{m}$ или n, чтобы избежать путаницы при чтении текста. Вполне возможно, что впоследствии писатели перенесли эту тенденцию и на другие комбинации букв в слове. Таким образом, несмотря на борьбу за исконное правописание заимствованной лексики и отвержение фонетического письма Дж. Харта, изменениям подвергся немалый пласт лексики. Заметим также тот момент, что в текстах начала и середины 17 века нами были обнаружены примеры обратной субституции -i- на -у- в исконно германских словах (day, way, always). Мы объясняем это предположением о том, что французский пласт лексики настолько прочно укоренился в языке, что, бывшие некогда вкраплениями, эти слова, а точнее их правописание, начали воздействовать и на правописание исконно германской лексики. Кроме того, вновь заставляет обратить на себя внимание факт 
практического отсутствия грамматик и словарей, помогающих разъяснить писателю эти тонкости орфографии, связанные с историей языка.

Проследим поэтапно процесс унификации субституции -у- на -і- для английского языка.

\section{- начало 17 века:}

"Th'imperiall ioyntresse to this warlike State" (W. Shakespeare, The Tragicall Historie of Hamlet. Prince of Denmarke, 1601);

"Sir, this unfortunate child, who in eight daies..." (F. Beaumont, The knight of the burning pestle, 1613);

"You cannot speake of reason to the Dane and lose your voyce" (W. Shakespeare, The Tragicall Historie of Hamlet. Prince of Denmarke, 1601);

В первом приведенном примере считаем необходимым отметить, что на тот период становления языка графемы $і$ и ј были взаимозаменяемы. Разница между ними была закреплена как языковая норма в ходе развития орфографии 17 века, а динамика унификации правописания в подобных случаях будет отражена в дальнейших примерах.

Во втором приведенном примере обратим внимание на то, о чем упоминали до этого - на влияние французской орфографии на исконно английскую лексику, берущую начало в прагерманском языке. К примеру, существительное day (dages from Proto-Germanic). Точную причину присутствия графемы -е на конце слова установить не представляется возможным, однако предполагаем, что это объясняется все теми же процессами, описанными выше.

- середина 17 века:

"... and the Joynts, but so many Wheeles..." (T. Hobbes, Leviathan, 1651);

"...being both rich in the nature of the Soil..."(J.Harrington, Oceana, 1656);

"I will consider them first Singly, and afterwards in Trayne..." (T. Hobbes, Leviathan, 1651);

- конец 17 века:

"...turning out with the Tyde of Ebb", "... and when we were got so high as the Tide flows..." (W. Dampier, A new voyage round the world, 1697);

"...but were deliver'd in the small still Voice of Blessing and Consolation" (J. Norris, Christian Blessedness or discourses upon the beatitudes of our Lord and Saviour Jesus Christ, 1692);

"... that had been cut and was join'd together" (W. Dampier, A new voyage round the world, 1697) - "...thought it expedient to joyn them both together in the Discourse" (J. Norris, Christian Blessedness or discourses upon the beatitudes of our Lord and Saviour Jesus Christ, 1692).
Как показано в вышеуказанных примерах, в середине столетия использование графемы -і- вместо -у- еще далеко от общепризнанной нормы. Затем в конце столетия У. Дампье использует два варианта написания слова практически на одной странице своего произведения, а затем вновь возвращается к варианту с -у-. Однокоренная слову join лексика используется в конце столетия также в обоих вариантах. Таким образом, колебания в понимании этого явления стали заметны, но потребуется еще некоторое время на завершение стандартизации.

Во французском языке субституция гласной -у на -i, особенно в конечной позиции, прошла более гладко. Причиной тому стало двойное чтение гласной у: в положении между двумя гласными она соответствует двум звукам і, из которых один образует звуко-буквенное сочетание с предыдущей гласной, а второй выражается йотированным звуком, объединяясь с последующей гласной. Таким образом, Академия заменила -у- на -і- в тех случаях, где гласная не указывала на двойное чтение и могла быть прочитана только одним способом.

- начало 18 века:

"...ou pour lui faire épouser par force une Dame avec laquelle ils venoient de le surprendre " (A.-R. Lesage, Le Diable boiteux, 1707 г.). При этом на этой же странице книги: “...il n'avoit pris la suite que pare qu'ils luy avoient enlevé son épée dans son combat" (A.-R. Lesage, Le Diable boiteux, 1707 r.);

"...c'est pourquoy sans s'y arrêter, il continua les réflexions " (A.-R. Lesage, Le Diable boiteux, 1707 г.);

"... les bons effets que j'ay éprouvez" (N. de Campion, Entretiens sur divers sujets d'histoire, de politique et de morale, 1704), наряду с эти в этом же издании у - показатель двойного чтения "...employoit tout son credit et toute son industrie pour la Liberté d'un Guerrier ";

"HUY. adv. D'huy en un mois " (Le Dictionnaire de l'Académie françoise dedié au Roy, 1694).

- середина 18 века:

"Mais un Bijou né voluptueux, se dompte rarement de luimême " (D. Diderot, Les bijoux indiscrets, 1748);

"Et puis Messieurs les Senateurs vont le priver de sa joye... " (D. Diderot, Les bijoux indiscrets, 1748);

"...si j'avois pû remonter plus haut : j'ai cité aussi un peuple moderne... "(J.-J. Rousseau, Observations de J.-J. Rousseau, de Geneve, 1751);

"ICl. adv.de lieu. En ce lieu-ci. Venez ici... " ( Dictionnaire de I'Académie françoise..., 1762).

- конец 18 века:

"Oui, la liberté est attaquée, menacée, dechirée... " (Dujardin de Beaumetz, Le cri du patriotisme, 1797);

"A présent, tu le sais, nous n'avons guère que le nécessaire de chaque jour " $(\mathrm{H}$. Bernardin de Saint-Pierre, Paul et Virginie, 1789);

"Je puis assurer que celles dont je vais parler ont vraiment 
existé... " (H. Bernardin de Saint-Pierre, Paul et Virginie, 1789);

"JOIE. s. f. Grande joie. Joie extraordinaire... "(Dictionnaire de l'Académie française, 1798).

В начале столетия использование -у- было неопределенным - на одной странице произведения можно было встретить два варианта написания одного и того же слова. По нашим приблизительным подсчетам, написание lиу встретилось в $40 \%$ случаев, соответственно написание lui примерно равно 60\%. 3-е издание словаря Французской Академии, выпущенное в 1740 г., впервые зафиксировало субституцию, и, как наглядно видно из примеров, в середине века в подавляющей части случаев писатели уже придерживались новых норм. К концу века норма окончательно устоялась.

Итак, в данной статье мы постарались кратко изложить результаты своего исследования истории субституции графем -у- и -і-. Для этого понадобилось изучить в каждом временном периоде язык нескольких литературных произведений, зафиксировать найденные отличия в правописании и постараться дать объяснение на каждом этапе. Приводим ниже таблицу с обобщенными данными по каждому языку и итоги.

\begin{tabular}{|c|c|c|c|c|}
\hline & $\begin{array}{c}\text { начало рассматриваемого } \\
\text { периода }\end{array}$ & $\begin{array}{c}\text { середина рассматриваемого } \\
\text { периода }\end{array}$ & $\begin{array}{c}\text { конец рассматриваемого } \\
\text { периода }\end{array}$ & итог \\
\hline $\begin{array}{c}\text { субституция графемы -y- } \\
\text { на -і- в английском языке }\end{array}$ & исходное написание & $\begin{array}{c}\text { добавляется вариативное } \\
\text { написание }\end{array}$ & $\begin{array}{c}\text { вариативное написание } \\
\text { преимущественно } \\
\text { сохраняется }\end{array}$ & $\begin{array}{c}\text { унификация } \\
\text { не завершилась }\end{array}$ \\
\hline $\begin{array}{c}\text { субституция графемы } \\
\text {-у-на -і- во французском } \\
\text { языке }\end{array}$ & $\begin{array}{c}\text { исходное написание } \\
\text { средкими вариациями }\end{array}$ & $\begin{array}{c}\text { частотное вариативное } \\
\text { написание и исходное } \\
\text { написание }\end{array}$ & $\begin{array}{c}\text { укрепляется новое } \\
\text { написание }\end{array}$ & унификация \\
завершилась
\end{tabular}

\section{ЛИТЕРАТУРА}

1. Блинов Р.Ю. Регистрация орфографии английского языка в орфографических словарях и справочниках / Р.Ю. Блинов // Вестник Гуманитарного факультета ИГХТУ. - 2009. - №4. - С. 220 - 224.

2. Ильиш Б.А. История английского языка / Б.А. Ильиш. - М.: Высшая Школа, 1986. - 419 с.

3. Катагощина Н.А. История французского языка / Н.А. Катагонщина, М.С. Гурычева, К.А. Аллендорф // М.: Изд-во литературы на иностранных языках. 1963. -447 c.

4. Полянская Л.П. Французская орфография в ретроспективе // Научно-методический электронный журнал «Концепт». - 2016. - Т. 15. - С. 2066-2070. URL: http://e-koncept.ru/2016/96333.htm.

5. Электронный ресурс: Словарь французского языка, датируемый концом 19 века Dictionnaire Le Littré. - URL: https://www.littre.org (дата обращения: 16.04.2018).

6. Электронный ресурс: Онлайн-архив различных словарей множества языков мира LEXILOGOS. - URL: https://www.lexilogos.com/index.htm (дата 0бращения: 20.04.2018).

7. Académie française. Dictionnaire de I'Académie française. Cinquième édition. Tome premier A-K / Paris : J. J. Smits et C. Imp.-Lib., rue de Tournon, N 1134 , Faubourg Germain, - 1798. - $768 \mathrm{p}$.

8. Académie française. Dictionnaire de l'Académie française. Cinquième édition. Tome second L-Z / Paris : J. J. Smits et C. Imp.-Lib., rue de Tournon, N 1134, Faubourg Germain. - 1798. $-776 \mathrm{p}$.

9. Beaumetz. Dujardin de. Le Cri du patriotisme / Dujardin de Beaumetz. - Paris, 1797. - $16 \mathrm{p}$.

10. Beaumont B. The knight of the burning pestle / F. Beaumont // London: Burre. $-1613 .-84 \mathrm{p}$.

11. Campion N. de. Entretiens sur divers sujets d'histoire, de politique et de morale / N. de Campion. - Paris, 1704. - $476 \mathrm{p}$.

12. Dampier W.A new voyage round the world / W. Dampier // London: Printed for James Knapton. - 1697. - 611 p.

13. Defoe D. Robinson Crusoe [электронный ресурс]. Режим доступа: http://www.literaturepage.com/read/robinsoncrusoe.html (дата 0бращения: 18.09.2017).

14. Dictionnaire de I'Académie françoise. Troisiéme édition. Tome premier A-K / Paris : Jean - Baptise Coignard, I'Imprimeur du Roy et de l'Académie Françoise, 1740. $-883 p$.

15. Dictionnaire de l'Académie françoise... Quatriéme édition. Tome premier A-T / Paris : Bernard Brunet, I'Imprimeur de l'Académie Françoise, 1762.

16. Diderot D. Les bijoux indiscrets / D. Diderot. - Paris, $1748-370 \mathrm{p}$.

17. Jacques-Bernardin-Henri de Saint-Pierre. Paul et Virginie / Jacques-Bernardin-Henri de Saint-Pierre / Paris : I'Imprimerie de Monsieur. - 1789. - 243 p.

18. Juric D. The historical development of the English spelling system / D. Juric // Osijek. - 2013. - p. 55.

19. Harrington J. The Oceana and other works / J. Harrington / London: A. Miller. - 1747. - $289 \mathrm{p}$.

20. Hobbes T. Leviathan / T. Hobbes // 1651. - 593 p.

21. Le Dictionnaire de I'Académie françoise dedié au Roy. Tome premier A-L / Paris: Jean - Baptise Coignard, I'Imprimeur et Libraire ordinaire du Roy, 1694 . - 694 p. 
22. Lesage A.-R. Le Diable boiteux / A.-R. Lesage. - Paris, 1707. - 314 p.

23. Mabru C.-A. Quelques réflexions sur le moment présent / C.-A. Mabru // 1799. - p. 45.

24. Norris J. Christian blessedness: or, discourses upon the Beatitudes of our Lord and Saviour Jesus Christ / J. Norris // London: Printed for S. Manship. - 1692. - 250 p.

25. Rousseau J.-J. Observations de J.-J. Rousseau, de Geneve / J.-J. Rousseau / Paris. - 1751 - 62 p.

26. Shakespeare W. Hamlet / W. Shakespeare // London: S. Low, son, and co. - 1860. - 248 p.

с Смахтина Юлия Вадимовна (juiasmahtina@mail.ru), Агеева Анастасия Владимировна (anastasia_ageeva@mail.ru),

Яхина Рузиля Раифовна (RRYakhina@kai.ru).

Журнал «Современная наука: актуальные проблемы теории и практики»

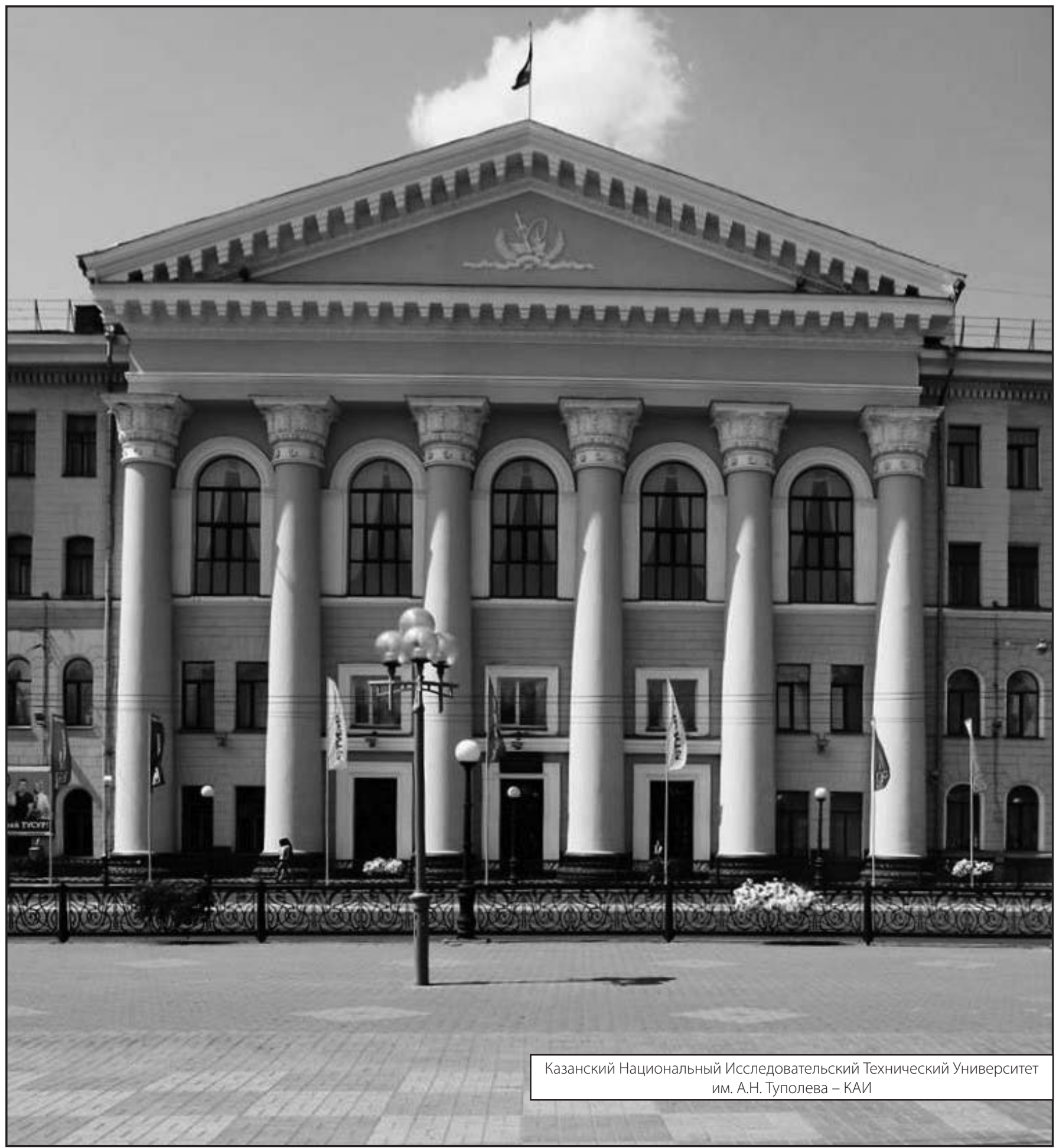

